\title{
TITLE:
}

\section{Cyclical growth in a Goodwin-Kalecki-Marx model}

$\operatorname{AUTHOR}(S)$ :

Sasaki, Hiroaki

\section{CITATION:}

Sasaki, Hiroaki. Cyclical growth in a Goodwin-Kalecki-Marx model. Journal of Economics 2013, 108(2): 145-171

ISSUE DATE:

2013-03

URL:

http://hdl.handle.net/2433/172450

\section{RIGHT:}

The final publication is available at www.springerlink.com; This is not the published version. Please cite only the published version.; この論文 は出版社版でありません。引用の際には出版社版をご確認ご利用くだ さい。 


\title{
Cyclical Growth in a Goodwin-Kalecki-Marx Model
}

\author{
Hiroaki SASAKI \\ Graduate School of Economics, Kyoto University \\ Yoshida-Honmachi, Sakyo-ku \\ Kyoto 606-8501, Japan \\ E-mail: sasaki@econ.kyoto-u.ac.jp \\ Phone: +81-(0)75-753-3446
}

\begin{abstract}
This paper presents a disequilibrium macrodynamic model that incorporates certain elements from Goodwin (the dynamics of the rate of employment and income distribution), Kalecki (an investment function independent of savings, and mark-up pricing in oligopolistic goods markets), and Marx (the reserve-army and reserve-army-creation effects). The model has a system of differential equations for the rate of utilization, profit share, and rate of employment. We show that there exist limit cycles that depend on the sizes of the reserve-army effect and reserve-army-creation effect. This implies that there exists a situation in which the economy experiences endogenous and perpetual growth cycles. Moreover, we show that if the stable long-run equilibrium corresponds to the profit-led growth regime, an increase in the bargaining power of workers increases the rate of unemployment; conversely, if the equilibrium corresponds to the wage-led growth-regime, an increase in the bargaining power of workers decreases the rate of unemployment.
\end{abstract}

Keywords: Goodwin-Kalecki-Marx model; cyclical growth; reserve-army-creation effects; Hopf bifurcation

JEL Classification: E12; E24; E25; E32; O41 


\section{Introduction}

This paper introduces a labor market and endogenous technical change to a Kaleckian model, which is a kind of disequilibrium macrodynamic model; investigates how the output, income distribution, and employment are determined; and examines the stability of the long-run equilibrium.

To date, a number of models of growth cycles have been developed. This paper focuses on endogenous growth cycles. Mainstream theories of growth cycles show that even under dynamic optimization, cyclical fluctuations can be produced endogenously. ${ }^{1}$ In what follows, we consider two examples.

The first example is from Benhabib and Nishimura (1979). In dynamic optimization models with one state variable, a steady state equilibrium is a saddle point; consequently, cyclical fluctuations do not occur. However, in dynamic optimization models with more than two state variables, cyclical fluctuations can occur. The authors reveal this fact by using the Hopf bifurcation theorem. ${ }^{2}$

The second example is a model of growth cycles with innovation. Furukawa (2007) extends a variety expansion model à la Romer (1990) and shows that cyclical fluctuations occur endogenously. Specifically, he assumes that there is a lag between the invention of new products and their diffusion. This time lag produces period-by-period indeterminacy of expectations, leading to growth cycles. Similar models of growth cycles that emphasize innovation include Evans et al. (1998), variety expansion; Francois and Lloyd-Ellis (2003), quality ladder à la Grossman and Helpman (1991); and Wälde (2005), creative destruction à la Aghion and Howitt (1992).

These models assume the full utilization of capital and the full employment of labor. That is, although the time path of each endogenous variable shows cyclical fluctuations, the economy as a whole is always in equilibrium.

This paper investigates growth cycles by using a disequilibrium macrodynamic model that provides a viewpoint different from equilibrium macrodynamic models. After examining data for a real economy, it seems that the economy is in a situation in which capital is not fully utilized and labor is not fully employed, even in the long run. ${ }^{3}$ For example, Zipperer and Skott (2011) present long-run cyclical trends for the rate of capacity utilization and rate

\footnotetext{
${ }^{1}$ Here, we do not consider the real business cycle theory in which business cycles are produced through a stochastic shock.

${ }^{2}$ For a detailed analysis of this line of research, see Dockner and Feichtinger (1991).

${ }^{3}$ It goes without saying that even if the real economy is not in equilibrium, equilibrium macrodynamic models are still valid. The most important role of using equilibrium models is to provide an explanation on economic cycles and fluctuations that is explicitly based on people's economic incentives and decisions made in or out of the markets.
} 
of employment (and profit share) in the OECD that support the above observation. ${ }^{4}$

A typical example of a disequilibrium macrodynamic model is that of Goodwin (1967). Goodwin's model shows that with full capacity utilization, there exist clockwise cyclical fluctuations along closed orbits in the $(e, m)$-plane, where $e$ and $m$ denote the rate of employment and profit share, respectively. ${ }^{5}$ The empirical studies mentioned above show that in most countries, clockwise cycles are actually observed. That is, it is safe to say that clockwise cycles in the $(e, m)$-plane is a consensus. However, Goodwin's model assumes the validity of Say's law, which states that the goods market is always in equilibrium. Goodwin's model does not consider the disequilibrium of goods markets and hence cannot explain cyclical fluctuations of capacity utilization.

In contrast, Keynesian macrodynamic models that are founded on the principle of effective demand consider the disequilibrium of both the labor and goods markets. Because we are investigating output as well as employment, we also consider Keynesian macrodynamic models. Several types of Keynesian models have been produced for the purpose of analysis. For example, Yoshida (1999) and Sportelli (2000) built Harrodian models, while Skott (1989) presented a Kaldorian model.

In this paper, we consider the Kaleckian model (a class of Keynesian macrodynamic models), ${ }^{6}$ specifically the Kaleckian model that incorporates the theory of conflicting-claims inflation, because it emphasizes the importance of income distribution between classes. ${ }^{7}$ In the Kaleckian model incorporating conflicting-claims inflation, both the rate of capacity utilization and income distribution (wage share and profit share) are endogenously determined through the conflict between workers and firms.

However, even such extended models do not consider the labor market satisfactorily. ${ }^{8}$ The existing Kaleckian growth models assume an unlimited labor supply and that firms employ as many workers as they desire at the given wage rate. If, however, the labor supply

\footnotetext{
${ }^{4}$ Other empirical findings include Barbosa-Filho and Taylor (2006), long-run trends for the rate of capacity utilization in the US; Mohun and Veneziani (2008), long-run trends for the rate employment in the US; and Harvie (2000), long-run trends for the rate of employment in the OECD.

${ }^{5}$ For extensions of Goodwin's model, see Pohjola (1981), Wolfstetter (1982), Sato (1985), Foley (2003), Ryzhenkov (2009), Shah and Desai (1981), van der Ploeg (1987), Sportelli (1995), and Choi (1995).

${ }^{6}$ Kaleckian models have the following four characteristics (Lavoie 1992): (1) they comprise the investment function; (2) the prices relative to direct costs are influenced by a broad range of factors, often summarized by the phrase "degree of monopoly"; (3) marginal costs are assumed to be constant up to full capacity; and (4) the rate of capacity utilization is assumed to be generally below unity.

${ }^{7}$ The theory of conflicting-claims inflation was originally developed by Rowthorn (1977). For the theory of Kalecki, see Kalecki (1971). For Kaleckian models with conflicting-claims inflation, see also Lavoie (1992) and Cassetti (2003).

${ }^{8}$ Dutt (1992) is a rare case. He introduced the labor market into a Kaleckian model and investigated growth with business cycle. For Kaleckian models with a labor market, see also Lima (2004) and Velupillai (2006).
} 
grows at an exogenously given rate, there is no guarantee that the endogenously determined employment growth will equal the exogenous labor supply growth. If the labor supply grows faster than the employment demand, then the rate of unemployment continues to rise; this is an unrealistic finding. Hence, such a model cannot suitably investigate long-run unemployment.

On the basis of the above observation, we present a Kaleckian model in which excess capacity is retained and cyclical growth never disappears, not even in the long run. ${ }^{9}$ For this purpose, we endogenize the labor-saving technical progress. By this extension, we demonstrate the existence of a situation in which the economy experiences endogenous and perpetual growth cycles.

We assume that the growth rate of labor productivity positively depends on the rate of employment. This assumption is based on Bhaduri (2006), Dutt (2006), and Flaschel and Skott (2006). Given the level of output, an increase in labor productivity lowers employment and thus gives rise to the Marxian concept of the reserve army of labor, that is, the unemployed. Because, from our specification, the growth rate of labor productivity increases with the rate of employment, a counterbalancing effect that lowers the increased rate of employment is exerted. We call this effect the "reserve army creation effect." ${ }^{10} \mathrm{~K}$. Marx emphasizes the role of labor-saving technological progress in the creation of the reserve army of labor (Marx, 1976; chs. 10, 13, and 23). We use this term to distinguish it from the "reserve army effect": that the growth rate of the wage is increasing in the rate of employment. We show that the interaction between the reserve army effect and reserve army creation effect produces limit cycles.

Contrary to the general belief, few studies simultaneously consider the three variables: rate of capacity utilization, rate of employment, and profit share. According to the findings of Zipperer and Skott (2011), in the US economy, clockwise cycles consistently exist in the $(u, m)$ - and $(e, u)$-planes as well as in the $(e, m)$-plane, where $u$ denotes the rate of capacity utilization. In relation to this finding, Skott and Zipperer (2010) develop a three-dimensional Kaldorian model that explains clockwise cycles in the three planes.

However, as Zipperer and Skott (2011) correctly state, counterclockwise cycles in the $(u, m)$ - and $(e, u)$-planes are also observed, except in the US. Figures 1-3 show time-connected scatterplots of the rate of employment, rate of capacity utilization, and profit share by using quarterly data for Japan during the period 1960-2007. ${ }^{11}$ The dotted circles in Figures 1-3

\footnotetext{
${ }^{9}$ Raghavendra (2006) proves the existence of endogenous and perpetual business cycles in a Kaleckian model. However, his model is a short-run model that does not consider the labor market and economic growth.

${ }^{10}$ For Kaleckian models with the reserve army creation effect, see also Sasaki $(2010,2011)$.

${ }^{11}$ The data for the rate of employment are taken from the Labour Force Survey, those for the profit share from the Financial Statements Statistics of Corporation by Industry, and those for the rate of capacity utilization from
} 
correspond to counterclockwise cycles. From these figures, we see that unlike in the US, clockwise cycles are not always dominant in Japan. Therefore, the directions of cycles can differ for countries and periods. Our model produces clockwise cycles in the $(e, m)$-plane but counterclockwise cycles in the $(u, m)$ - and $(e, u)$-planes. In this sense, the model is consistent with some empirical findings.

[Figures 1-3 around here]

Since our model incorporates certain elements from Goodwin (the dynamics of the rate of employment and income distribution), Kalecki (an investment function independent of savings and mark-up pricing in oligopolistic goods markets), and Marx (the reserve army and reserve army creation effects). For this reason, we call our model a Goodwin-KaleckiMarx model.

The remainder of the paper is organized as follows. Section 2 presents the framework of the model and derives the fundamental equations for the analysis. Section 3 analyzes the long-run equilibrium, shows that a limit cycle can occur, and conducts a comparative statics analysis. Section 4 shows the existence of limit cycles through the use of numerical simulations. Section 5 concludes the paper.

\section{Basic framework of the model}

Consider an economy with workers and capitalists. Suppose that workers spend all their wages and capitalists save a constant fraction $s$ of their profits. Let $r$ and $K$ be the rate of profit and capital stock, respectively. Then, the real savings are given by $S=s r K$, and accordingly, the ratio of real savings to capital stock, $g_{s}=S / K$, yields

$$
g_{s}=s r .
$$

We ignore capital depreciation for simplicity.

Suppose that the firms operate with the following fixed coefficients production function:

$$
Y=\min \{a L,(u / k) K\},
$$

where $Y$ denotes real output; $L$, employment; and $a=Y / L$, the level of labor productivity. The rate of capacity utilization is defined as $u=Y / Y^{*}$, where $Y^{*}$ denotes the potential output. The coefficient $k=K / Y^{*}$ denotes the ratio of capital stock to potential output, which

the Indices of Industrial Production. These quarterly data are smoothed by the Hodrick-Prescott filter with a smoothing parameter $\lambda=1600$. 
is assumed to be constant. This assumption implies that both $K$ and $Y^{*}$ grow at the same rate. Moreover, when the rate of capacity utilization is constant, the growth rates of capital stock and actual output are the same. Accordingly, the actual output and potential output grow at the same rate in the long-run equilibrium. To simplify the analysis, we assume $k=1$ in what follows. The main results in this paper do not change as long as $k$ is assumed to be constant. From this, we have $r=m u$, where $m$ denotes the profit share.

Based on the argument of Marglin and Bhaduri (1990), we specify the ratio of real investment $I$ to capital stock $K, g_{d}=I / K$, as a function that is increasing in both the profit share and the rate of capacity utilization. ${ }^{12}$ In particular, following Blecker (2002), we specify the investment function as follows:

$$
g_{d}=\psi m^{\beta} u^{\gamma}, \quad \psi>0, \beta \in(0,1), \gamma \in(0,1),
$$

where $\psi$ denotes a constant; $\beta$, the elasticity of the investment rate with respect to the profit share; and $\gamma$, the elasticity of the investment rate with respect to the rate of capacity utilization. Equation (3) implies that the desired investment rate of firms is increasing in both the profit share and the rate of capacity utilization. The parameter restriction $0<\gamma<1$ ensures that, evaluated at the equilibrium, investment is less sensitive than saving to variations in the rate of utilization. ${ }^{13}$ Because the investment function is not linear but Cobb-Douglas, as will be shown later, different regimes can be produced by changing the sizes of $\beta$ and $\gamma$. When $\beta<\gamma$, the long-run equilibrium is wage-led growth, whereas when $\beta>\gamma$, it is profit-led growth. The equilibrium is said to be wage-led (profit-led) growth if a rise in the profit share leads to a fall (rise) in the rate of capital accumulation. ${ }^{14}$

An equation of motion for the rate of capacity utilization is given by

$$
\dot{u}=\alpha\left(g_{d}-g_{s}\right), \quad \alpha>0,
$$

\footnotetext{
${ }^{12}$ The reason for this is as follows. The rate of profit is equal to the product of the profit share and the rate of capacity utilization, that is, $r=m u$. Thus, it is plausible that a combination of high capacity utilization and a low profit share and a combination of low capacity utilization and a high profit share will produce different levels of investment even when the rate of profit is held constant at a given level.

${ }^{13}$ However, there is a view that the long-run parameter restrictions in the Kaleckian investment function have neither theoretical nor empirical support. See Skott (2012).

${ }^{14}$ In this paper, the profit share is an endogenous variable, and not an exogenous variable, and thus, we cannot define $\partial g^{*} / \partial m$ at the equilibrium. Accordingly, we use the relationship between $g^{*}$ and the parameter $m_{f}$ (the target profit share of firms introduced later). Hence, the equilibrium is wage-led growth if $\partial g^{*} / \partial m_{f}<0$ and profit-led growth if $\partial g^{*} / \partial m_{f}>0$. As seen from equation (A-19), the sign of $\partial g^{*} / \partial m_{f}$ depends on the relative sizes of $\beta$ and $\gamma$. If $\beta>1$ in this specification, we have the exhilarationist regime in which an increase in the profit share leads to a rise in the rate of capacity utilization. However, $\beta>1$, as Blecker (2002) points out, is an extreme case. Hence, we assume $0<\beta<1$ in the following analysis.
} 
where $\alpha$ denotes the speed of adjustment of the goods market. Equation (4) shows that excess demand leads to a rise in the rate of capacity utilization, while excess supply leads to a decline in the rate of capacity utilization.

From the definition of profit share, we have $m=1-(w L / p Y)$, from which we obtain the following relation: ${ }^{15}$

$$
\frac{\dot{m}}{1-m}=\frac{\dot{p}}{p}-\frac{\dot{w}}{w}+\frac{\dot{a}}{a}
$$

where $w$ denotes the money wage and $p$, the price. To know the dynamics of $m$, we have to specify the dynamics of $p, w$, and $a$.

We specify the dynamics of the money wage and price by using the theory of conflictingclaims inflation. First, suppose that the growth rate of the money wage that workers manage to negotiate depends on the discrepancy between their target profit share and the actual profit share. Second, suppose that the firms set their price to close the gap between their target profit share and the actual profit share. From these considerations, the dynamics of the money wage and price can be described, respectively, as follows:

$$
\begin{array}{ll}
\frac{\dot{w}}{w}=\theta_{w}\left(m-m_{w}\right), & \theta_{w}>0, m_{w} \in(0,1), \\
\frac{\dot{p}}{p}=\theta_{f}\left(m_{f}-m\right), & \theta_{f}>0, m_{f} \in(0,1),
\end{array}
$$

where $\theta_{w}$ and $\theta_{f}$ denote the speed of adjustment; $m_{w}$, the target profit share set by workers; and $m_{f}$, the target profit share set by firms. In equations (6) and (7), expected price- and wage inflations are not explicitly considered. However, even if inflationary expectations are introduced, we obtain similar results given the perfect foresight (see Dutt, 1992). Therefore, the present simple specification suffices for our purpose. In equation (7), it is assumed that firms are unable to set the markup at the level that they consider optimal. According to Lavoie (1992), in historical time, prices do not always follow wages. For example, firms have to publish price lists in advance before wage bargaining is over. In addition, firms face constraints on prices that are not considered in the present model such as foreign competition. Hence, it is difficult for firms to set the optimal markup.

We can interpret $\theta_{w}$ and $\theta_{f}$ as the bargaining powers of the workers and firms, respectively. ${ }^{16}$ We assume $\theta_{f}+\theta_{w}=1$ and define $\theta_{f} \equiv \theta$ because bargaining power is a relative

\footnotetext{
${ }^{15}$ Cassetti (2003) derives an equation of motion for the profit share by specifying a price-setting equation of firms and differentiating it with respect to time. However, this procedure is unnecessary for deriving the dynamics of the profit share, and our procedure is easier than his. Under the conflicting-claims inflation theory, the price-setting equation in Cassetti's model plays the role of determining the mark-up rate, and not the price level.

${ }^{16}$ This interpretation is also adopted in Lavoie (1992, p. 393) and Cassetti (2003, p. 453).
} 
concept. Then, we have $\theta_{w}=1-\theta$, where $0<\theta<1 .{ }^{17}$ For example, we consider an increase in the unionization rate as a factor in increasing the bargaining power of workers (i.e., a decrease in $\theta$ ), and an increase in the market power of oligopolistic firms as a factor in increasing the bargaining power of firms (i.e., an increase in $\theta$ ).

We assume that the workers' target $m_{w}$ depends negatively on the rate of employment, $e$.

$$
m_{w}=m_{w}(e), \quad m_{w}^{\prime}<0,
$$

Here, $e=L / N$ and $N=N_{0} e^{n t}$ denotes the exogenous labor supply, where $N_{0}$ is the initial value of labor supply and $n>0$ is the exogenously given growth rate of $N$. As the rate of employment increases, workers' demands in the bargaining are likely to increase, which leads workers to set a higher target wage share, and accordingly, set a lower target profit share. We consider equation (8) as expressing the "reserve-army effect." ${ }^{18}$ On the other hand, for simplicity, we consider the firms' target profit share $m_{f}$ as exogenously given. ${ }^{19}$ Notice the difference between $\theta$ and equation (8). The parameter $\theta$ represents the relative bargaining power of firms (workers) and reflects the power to realize their demands. In contrast, equation (8) reflects their demands in the bargaining. To what extent their demands can be realized depends on $\theta$.

From equation (2), the rate of employment is given by $e=u K /(a N)$, and hence, the rate of change in the rate of employment yields

$$
\frac{\dot{e}}{e}=\frac{\dot{u}}{u}+g_{d}-g_{a}-n
$$

where $n$ is the growth rate of $N$ and given exogenously, and $g_{a}=\dot{a} / a$.

As stated above, we assume that the growth rate of labor productivity depends positively on the rate of employment. ${ }^{20}$

$$
g_{a}=g_{a}(e), \quad g_{a}^{\prime}>0, g_{a}>0 .
$$

This equation includes the reserve-army-creation effect. ${ }^{21}$ Based on the idea of Marx, Bhaduri (2006) states that this formulation captures the view that technological change is

\footnotetext{
${ }^{17}$ The constraints $0<\theta_{w}, \theta_{f}<1$ are also adopted by Dutt and Amadeo (1993), who, however, do not assume $\theta_{f}+\theta_{w}=1$. Even if we impose only $0<\theta_{w}, \theta_{f}<1$ and not $\theta_{f}+\theta_{w}=1$, we can obtain similar results.

${ }^{18}$ Cassetti (2003) also considers such a reserve-army effect in the Kaleckian framework.

${ }^{19} \mathrm{We}$ can endogenize the target profit share of firms. Lima (2004) assumes that $m_{f}$ is an increasing function of $u$.

${ }^{20}$ The adoption of a new technology entails cost. The purpose of this paper is to analyze the effect of induced technical progress arising from demand factors on the stability of the economy, and not to investigate the consequences of resource allocation to R\&D sectors. Therefore, we neglect the adoption cost of technology.

${ }^{21}$ We can also interpret that Equation (10) is obtained through the learning-by-doing effect à la Arrow (1962). If the level of labor productivity is increasing in the production experience and the experience is measured by
} 
driven by inter-class conflict over income distribution between workers and capitalists. Dutt (2006) says that as the labor market tightens and labor shortage becomes clearer, the bargaining power of workers increases, which exerts an upward pressure on wages, leading capitalists to adopt labor-saving technical changes. The view that increases in wages induce labor-saving technical progress is consistent with an empirical study by Marquetti (2004), who investigates the co-integration between real wages and labor productivity and conducts Granger non-causality tests by using U.S. data. He shows that Granger non-causality tests support unidirectional causation from real wage to labor productivity. In determining technical change, mainstream growth theory emphasizes supply side factors such as R\&D investment and human capital accumulation. In contrast, this paper emphasizes the demand side factors contributing to technical change: changes in aggregate demand cause changes in employment, which leads to technical change.

In general, the natural rate of growth is defined as a sum of the growth rates of labor productivity and labor supply. Although the growth rate of labor supply in our model is exogenously given, the growth rate of labor productivity is endogenously determined. Under our specification, therefore, the natural rate of growth increases when business is good (i.e., when the employment rate is high) and it decreases when business is bad (i.e., when the employment rate is low). The assumption that the natural rate of growth is endogenously determined is consistent with the empirical studies of León-Ledesma and Thirlwall (2002) and Libânio (2009). ${ }^{22}$

We now focus on the derivation of the system of differential equations. First, substituting equations (1) and (3) in equation (4), we obtain the dynamics of $u$. Second, substituting equations (6) and (7) in equation (5), and substituting equations (8) and (10) in the resulting expression, we obtain the dynamics of $m$. Finally, substituting the dynamics of $u$, equation (3), and equation (10) in equation (9), we obtain the dynamics of $e$.

$$
\begin{aligned}
\dot{u} & =\alpha\left(\psi m^{\beta} u^{\gamma}-s m u\right), \\
\dot{m} & =-(1-m)\left[m-\theta m_{f}-(1-\theta) m_{w}(e)-g_{a}(e)\right], \\
\dot{e} & =e\left[\alpha\left(\psi m^{\beta} u^{\gamma-1}-s m\right)+\psi m^{\beta} u^{\gamma}-g_{a}(e)-n\right] .
\end{aligned}
$$

the cumulative sums of the employment rate, then the growth rate of labor productivity is increasing in the employment rate. Moreover, this specification apparently relates to Verdoorn's law and also to Okun's law. In this paper, however, we emphasize the route that a rise in the rate of employment makes firms adopt laborsaving technology.

${ }^{22}$ León-Ledesma and Thirlwall (2002) empirically investigate whether the natural growth rate is exogenous or endogenous to demand and whether it is input growth that causes output growth or vice versa. This question lies at the heart of the debate between neoclassical growth economists and economists in the Keynesian/postKeynesian tradition. Using the same method, Libânio (2009) empirically investigates Latin America and reaches similar conclusions. 
We now provide an explanation with regard to the structure of our model. If we introduce $m_{w}=m_{w}(e)$ with $g_{a}$ as exogenously given, we find that the rate of employment is endogenously determined whereas the natural rate of growth is exogenous. If we, on the other hand, introduce $g_{a}=g_{a}(e)$ with $m_{w}$ as exogenously given, we find that both the rate of employment and the natural rate of growth are endogenously determined. Hence, to endogenize both the rate of employment and the natural rate of growth, we do not need to specify $m_{w}$ as a function of $e$. Nevertheless, we use both $g_{a}(e)$ and $m_{w}(e)$. This is because we intend to capture the interaction between the reserve-army and reserve-army-creation effects.

\section{Long-run equilibrium analysis}

\subsection{Existence of the long-run equilibrium}

The long-run equilibrium is a situation where $\dot{u}=\dot{m}=\dot{e}=0$. Here, we have the following three equations:

$$
\begin{aligned}
& \psi m^{\beta} u^{\gamma}-s m u=0, \\
& m-\theta m_{f}-(1-\theta) m_{w}(e)-g_{a}(e)=0, \\
& \psi m^{\beta} u^{\gamma}-g_{a}(e)-n=0 .
\end{aligned}
$$

These equations show that the equilibrium values do not depend on the speed of adjustment, $\alpha$. From equation (14), we obtain

$$
u=\left(\frac{\psi}{s}\right)^{\frac{1}{1-\gamma}} m^{\frac{\beta-1}{1-\gamma}} .
$$

Substituting equation (17) in equation (16), we find that the resulting expression will be an equation of $m$ and $e$. Combining this equation with equation (15), we can obtain the equilibrium values of $m$ and $e$, which are substituted in equation (17) to find the equilibrium value of $u$. In the following analysis, we assume that there uniquely exist long-run equilibrium values $\left(u^{*}, m^{*}, e^{*}\right)$ that satisfy equations (14), (15), and (16) simultaneously. In addition, we assume $u^{*}, m^{*}, e^{*} \in(0,1)$. Hereafter, the long-run equilibrium values are denoted with "*."

\subsection{Local stability of the long-run equilibrium}

To investigate the local stability of the long-run equilibrium, we linearize the system of differential equations (11), (12), and (13) around the equilibrium.

$$
\left(\begin{array}{c}
\dot{u} \\
\dot{m} \\
\dot{e}
\end{array}\right)=\left(\begin{array}{ccc}
J_{11} & J_{12} & 0 \\
0 & J_{22} & J_{23} \\
J_{31} & J_{32} & J_{33}
\end{array}\right)\left(\begin{array}{c}
u-u^{*} \\
m-m^{*} \\
e-e^{*}
\end{array}\right),
$$


where the elements of the Jacobian matrix $\mathbf{J}$ are given by

$$
\begin{aligned}
& J_{11} \equiv \frac{\partial \dot{u}}{\partial u}=-\alpha s(1-\gamma) m<0, \\
& J_{12} \equiv \frac{\partial \dot{u}}{\partial m}=-\alpha s(1-\beta) u<0, \\
& J_{22} \equiv \frac{\partial \dot{m}}{\partial m}=-(1-m)<0, \\
& J_{23} \equiv \frac{\partial \dot{m}}{\partial e}=(1-m) \underbrace{\left[(1-\theta) m_{w}^{\prime}(e)+g_{a}^{\prime}(e)\right]}_{\equiv \Gamma(e, \theta)}=(1-m) \Gamma(e, \theta) \gtrless 0, \\
& J_{31} \equiv \frac{\partial \dot{e}}{\partial u}=\operatorname{sme}\left[\frac{\alpha(\gamma-1)+\gamma u}{u}\right] \gtrless 0, \\
& J_{32} \equiv \frac{\partial \dot{e}}{\partial m}=\operatorname{se}[\alpha(\beta-1)+\beta u] \gtrless 0, \\
& J_{33} \equiv \frac{\partial \dot{e}}{\partial e}=-e g_{a}^{\prime}(e)<0 .
\end{aligned}
$$

All elements are evaluated at the long-run equilibrium; we omit " $*$ " to avoid troublesome notations.

The term $\Gamma(e, \theta) \equiv(1-\theta) m_{w}^{\prime}(e)+g_{a}^{\prime}(e)$ in equation (22) consists of the following three elements: the relative bargaining power of firms $\theta$, the extent of the reserve-army effect $m_{w}^{\prime}$, and the extent of the reserve-army-creation effect $g_{a}^{\prime}$. Because $m_{w}^{\prime}<0$ and $g_{a}^{\prime}>0, \Gamma$ can be positive or negative. When the reserve-army effect is strong (i.e., the absolute value of $m_{w}^{\prime}$ is large), and the bargaining power of firms and the reserve-army-creation effect are weak (i.e., $\theta$ and $g_{a}^{\prime}$, respectively, are small), we have $\Gamma<0$. On the other hand, when the reserve-army effect is weak, and the bargaining power of firms and the reserve-army-creation effect are strong, we have $\Gamma>0$. The sign of $\Gamma$ plays an important role in both the stability of the equilibrium and the comparative statics analysis below.

The signs of equations (23) and (24) are indeterminate. When $\alpha$ is sufficiently large, these signs are likely to be negative.

The characteristic equation of the Jacobian matrix (18) is given by

$$
\lambda^{3}+a_{1} \lambda^{2}+a_{2} \lambda+a_{3}=0
$$

where $\lambda$ denotes a characteristic root. Each coefficient of equation (26) is given by

$$
\begin{aligned}
& a_{1}=-\operatorname{tr} \mathbf{J}=-\left(J_{11}+J_{22}+J_{33}\right), \\
& a_{2}=\left|\begin{array}{ll}
J_{22} & J_{23} \\
J_{32} & J_{33}
\end{array}\right|+\left|\begin{array}{cc}
J_{11} & 0 \\
J_{31} & J_{33}
\end{array}\right|+\left|\begin{array}{cc}
J_{11} & J_{12} \\
0 & J_{22}
\end{array}\right|=J_{22} J_{33}-J_{23} J_{32}+J_{11} J_{33}+J_{11} J_{22}, \\
& a_{3}=-\operatorname{det} \mathbf{J}=-J_{11} J_{22} J_{33}+J_{11} J_{23} J_{32}-J_{31} J_{12} J_{23}
\end{aligned}
$$


where $-a_{1}=\operatorname{tr} \mathbf{J}$ denotes the trace of $\mathbf{J} ; a_{2}$, the sum of the principal minors' determinants; and $-a_{3}=\operatorname{det} \mathbf{J}$, the determinant of $\mathbf{J}$.

The necessary and sufficient condition for the local stability is that all characteristic roots of the Jacobian matrix have negative real parts, which, from Routh-Hurwitz condition, is equivalent to

$$
a_{1}>0, a_{2}>0, a_{3}>0, a_{1} a_{2}-a_{3}>0 .
$$

Let us examine whether these inequalities hold. We arrange the coefficients with respect to $\alpha$.

First, $a_{1}$ is a linear function of $\alpha$.

$$
a_{1} \equiv a_{1}(\alpha)=\underbrace{s(1-\gamma) m}_{\equiv A>0} \alpha+\underbrace{(1-m)+e g_{a}^{\prime}(e)}_{\equiv B>0}=\underset{+}{A \alpha} \alpha+\underset{+}{B} .
$$

Therefore, we can confirm that $a_{1}>0$. This implies that $\operatorname{tr} \mathbf{J}<0$, which is a necessary condition for the local stability of the equilibrium.

Second, $a_{2}$ is a linear function of $\alpha$.

$$
\begin{aligned}
a_{2} \equiv a_{2}(\alpha) & =\underbrace{\left\{s(1-\gamma) m\left[1-m+e g_{a}^{\prime}(e)\right]+s(1-\beta) e(1-m) \Gamma(e, \theta)\right\}}_{\equiv C \gtrless 0} \alpha \\
& +\underbrace{e(1-m)\left[(1-\beta s u) g_{a}^{\prime}(e)-s \beta(1-\theta) u m_{w}^{\prime}(e)\right]}_{\equiv D>0}={\underset{+/-}{C} \alpha+\underset{+}{D} .}^{e(1-s)}
\end{aligned}
$$

If $\Gamma>0$, we always have $C>0$. Hence, we obtain $a_{2}>0$. If, however, $\Gamma<0$, we do not always have $C>0$.

Third, $a_{3}$ is a linear function of $\alpha$.

$$
\begin{aligned}
a_{3} \equiv a_{3}(\alpha) & =s(1-\gamma) e m(1-m) \underbrace{\left[g_{a}^{\prime}(e)-\frac{s(\beta-\gamma)}{1-\gamma} u \Gamma(e, \theta)\right]}_{\equiv \Theta} \alpha \\
& =\underbrace{s(1-\gamma) e m(1-m) \Theta}_{\equiv E} \alpha=E \alpha .
\end{aligned}
$$

Finally, $a_{1} a_{2}-a_{3}$ is a quadratic function of $\alpha$.

$$
a_{1} a_{2}-a_{3} \equiv \phi(\alpha)=(A C) \alpha^{2}+(A D+B C-E) \alpha+\underbrace{B D}_{+} .
$$

At this stage, we cannot confirm whether this parabola is convex upward or convex downward. However, when $\alpha=0$, we have $\phi(0)=B D>0$, which shows that there exists an $\alpha$ such that $a_{1} a_{2}-a_{3}>0$ for $\alpha>0$.

Observing equations (31) through (34), we obtain the following proposition: 
Proposition 1. Suppose that $\Gamma>0$. Suppose also that the equilibrium profit share $m^{*}$ is less than or equal to $1 / 2$. Then, the long-run equilibrium is locally stable irrespective of the size of $\alpha$.

Proof. If $\Gamma>0$, and consequently $C>0, \phi(\alpha)$ becomes a parabola that is convex downward. Here, we focus on the coefficient of $\alpha$ in $\phi(\alpha)$, that is, $A D+B C-E$. Expanding this coefficient, we have

$$
A D+B C-E=\underbrace{s(1-\gamma) m\left[1-m+e g_{a}^{\prime}(e)\right]^{2}}_{+}+\underbrace{s(1-\beta) e(1-m) \Gamma}_{+}[\underbrace{e g_{a}^{\prime}(e)}_{+}+\underbrace{(1-m-s \gamma u m)}_{\equiv \Lambda}] .
$$

When $s, \gamma$, and $u$ are close to zero, $\Lambda \equiv 1-m-$ syum will be positive because syum will be sufficiently small. On the other hand, when $s, \gamma$, and $u$ are close to unity, $\Lambda$ approaches $\Lambda=1-2 m$. From this, if $m^{*} \leq 1 / 2$, we have $\Lambda \geq 0$. When $\Lambda \geq 0$, we have $A D+B C-E>0$, and consequently, we obtain $\phi(\alpha)>0$ for $\alpha>0$. Therefore, if $\Gamma>0$ and if $m^{*} \leq 1 / 2$, then the necessary and sufficient conditions for local stability, that is, $a_{1}>0, a_{2}>0, a_{3}>0$, and $a_{1} a_{2}-a_{3}>0$, are all satisfied.

Proposition 1 is obtained when the reserve-army effect is weak, and the relative bargaining power of firms and the reserve-army-creation effect are strong. In general, the profit share in the real world is considered to be less than $1 / 2$, and hence, condition $m^{*} \leq 1 / 2$ is plausible. Note, however, that $m^{*} \leq 1 / 2$ is a sufficient and not a necessary condition for $a_{1} a_{2}-a_{3}>0$. Moreover, $m^{*}$ depends on the parameters of the model.

Here, we introduce the following assumption:

Assumption 1. The sign of $\Theta$ in equation (33) is positive.

The sign of $a_{3}$ depends on the sign of $\Theta$. If $\Theta>0$, we have $E>0$, and consequently, $a_{3}>0$. This implies that $\operatorname{det} \mathbf{J}<0$, which is a necessary condition for the local stability of the equilibrium. When $\beta>\gamma$, we always have $\Theta>0$ irrespective of the sign of $\Gamma{ }^{23}$ However, when $\beta<\gamma$, we do not always have $\Theta>0$. When $\beta<\gamma$, we always have $\Theta>0$ if $\Gamma>0$. Even if $\Gamma<0$, we can have $\Theta>0$.

From this, we obtain the following proposition:

${ }^{23}$ Expanding $\Theta$, we obtain

$$
\Theta=\left(1-s u \frac{\beta-\gamma}{1-\gamma}\right) g_{a}^{\prime}(e)-s u \frac{\beta-\gamma}{1-\gamma}(1-\theta) m_{w}^{\prime}(e) .
$$

When $\beta>\gamma,(\beta-\gamma) /(1-\gamma)$ is larger than zero and smaller than unity. From this, the first term of the right-hand side is positive. The second term of the right-hand side is positive because $m_{w}^{\prime}<0$. Therefore, when $\beta>\gamma$, we have $\Theta>0$ irrespective of the sign of $\Gamma$. 
Proposition 2. Suppose that the speed of adjustment of the goods market $\alpha$ is sufficiently close to zero. Then, the long-run equilibrium is locally stable.

Proof. From the above discussion, we have $a_{1}>0$ and $a_{3}>0$. When $\alpha=0$, we have $\phi(0)=B D>0$, that is, $a_{1} a_{2}-a_{3}>0$. If $a_{1}>0, a_{3}>0$, and $a_{1} a_{2}-a_{3}>0$, then $a_{2}>0$ is necessarily satisfied. Hence, if $\alpha=0$, the necessary and sufficient conditions given by (30) are all satisfied. Because $\phi(\alpha)$ is a continuous function of $\alpha$, even if $\alpha>0, a_{1} a_{2}-a_{3}>0$ is satisfied when $\alpha$ is sufficiently close to zero. Therefore, when $\alpha$ is sufficiently close to zero, the necessary and sufficient conditions given by (30) are all satisfied.

Proposition 2 is obtained regardless of whether $\Gamma>0$ or $\Gamma<0$. That is, if the speed of adjustment of the goods market is very slow, the long-run equilibrium is locally stable irrespective of the size of the relative bargaining power of firms, the reserve-army effect, and the reserve-army-creation effect.

\subsection{Existence of closed orbits}

As explained above, if $\Gamma<0$, it is possible that $C<0$, which implies that the system is locally unstable. However, the instability of the steady state does not necessarily mean that the system will explode. If there exists a limit cycle, it is possible that the economy converges to a cyclical path.

Proposition 3. Suppose that $C<0$. Then, a limit cycle occurs when the speed of adjustment of the goods market lies within some range.

Proof. If $C<0, a_{2}(\alpha)$ becomes a straight line whose slope is negative and intercept is positive. This implies that there exists $\bar{\alpha}>0$ such that $a_{2}(\bar{\alpha})=0$. Moreover, if $C<0$, Descartes' rule of signs assures that the quadratic equation $\phi(\alpha)=0$ has one negative real root and one positive root. Since only the positive root has economic meaning, we let $\underline{\alpha}$ denote the positive root. Let us investigate which is larger, $\bar{\alpha}$ or $\underline{\alpha}$. From $a_{2}(\bar{\alpha})=0$, we obtain $\bar{\alpha}=-D / C>0$. Substituting $\bar{\alpha}$ in $\phi(\alpha)$, we obtain

$$
\phi(\bar{\alpha})=\frac{D E}{C}<0
$$

because $C<0$. This implies that $\underline{\alpha}<\bar{\alpha}$. From this, we get that $a_{1}>0, a_{2}>0, a_{3}>0$, and $a_{1} a_{2}-a_{3}>0$ within the range $\alpha \in(0, \underline{\alpha})$, while $a_{1}>0, a_{2}>0, a_{3}>0$, and $a_{1} a_{2}-a_{3}<0$ within the range $\alpha \in(\underline{\alpha}, \bar{\alpha})$. Consequently, a Hopf bifurcation occurs at $\underline{\alpha}$. Indeed, at $\alpha=\underline{\alpha}$, we obtain

$$
a_{1}>0, a_{2}>0, a_{3}>0, a_{1} a_{2}-a_{3}=0,\left.\frac{\partial\left(a_{1} a_{2}-a_{3}\right)}{\partial \alpha}\right|_{\alpha=\underline{\alpha}} \neq 0 .
$$


That is, all conditions for the occurrence of the Hopf bifurcation are satisfied. ${ }^{24}$ Therefore, when $C<0$, there exists a continuous family of non-constant, periodic solutions of the system around $\alpha=\underline{\alpha}$.

We obtain $C<0$ when $g_{a}^{\prime}$ and $\theta$ are small, and the absolute value of $m_{w}^{\prime}$ is large. These conditions are similar to the conditions for $\Gamma<0$. Indeed, $\Gamma<0$ is a necessary condition for $C<0$. From this, we can obtain Proposition 3 when the reserve-army effect is strong, and the relative bargaining power of firms and the reserve-army-creation effect are weak.

As explained above, the long-run equilibrium can be both stable and unstable. Let us briefly explain this mechanism. Here, we focus on the rate of capacity utilization. Suppose that the rate of capacity utilization exceeds its equilibrium value for some reason. Then, as long as the speed of adjustment of the goods market is not extremely large, the increase in the rate of capacity utilization induces the rate of employment to increase through equation (23). This increase in the rate of employment changes the profit share through equation (22). The direction of the change in the profit share depends on the sign of $\Gamma$.

If $\Gamma>0$, that is, the power of firms is relatively strong, then the profit share increases. This increase in the profit share has two opposing effects. (1) The increase in the profit share stimulates the investment of firms, which increases the output. (2) The increase in the profit share increases the savings of capitalists, which decreases the output. Because the adjustment process of the goods market is stable, the latter negative effect on the output is stronger than the former positive effect, and as a result, the output and the rate of capacity utilization decrease (see equation (20)). Therefore, here, a negative feedback effect acts on the rate of capacity utilization, and accordingly, the long-run equilibrium will be stable.

On the other hand, if $\Gamma<0$, that is, the power of workers is relatively strong, then the profit share declines, which increases the rate of capacity utilization through equation (20). Therefore, here, a positive feedback effect acts on the rate of capacity utilization, and accordingly, the long-run equilibrium will be unstable.

$$
u \uparrow \Longrightarrow e \uparrow(\text { when } \alpha \text { is not so large }) \Longrightarrow\left\{\begin{array}{lllll}
m \uparrow & (\Gamma>0) & \Longrightarrow & u \downarrow & \text { (stabilizing) } \\
m \downarrow & (\Gamma<0) & \Longrightarrow & u \uparrow & \text { (destabilizing) }
\end{array} .\right.
$$

Finally, we refer to the roles of the reserve-army and reserve-army-creation effects. When only the reserve-army-creation effect exists, that is, $m_{w}^{\prime}=0$, we always have $\Gamma=$ $g_{a}^{\prime}>0$. In this case, from Proposition 1, the long-run equilibrium is locally stable given that

\footnotetext{
${ }^{24}$ For the Hopf bifurcation theorem, see Gandolfo (2010). The last condition in equation (37), that is, $\partial\left(a_{1} a_{2}-a_{3}\right) /\left.\partial \alpha\right|_{\alpha=\underline{\alpha}} \neq 0$, is equivalent to the condition that the derivatives of the real parts of the characteristic roots with respect to $\alpha$ are not zero when evaluated at $\alpha=\underline{\alpha}$. For details, see Asada and Semmler (1995, pp. 634-635).
} 
$m^{*} \leq 1 / 2$, and accordingly, the Hopf bifurcation never occurs. Therefore, the reserve-armycreation effect has a stabilizing effect.

In contrast, when only the reserve-army effect exists, that is, $g_{a}^{\prime}=0$, we always have $\Gamma=(1-\theta) m_{w}^{\prime}<0$. In this case,

$$
\Theta=-\frac{s(\beta-\gamma)}{1-\gamma} u(1-\theta) m_{w}^{\prime} .
$$

If $\beta>\gamma$, then $\Theta>0$ necessarily holds. However, if $\beta<\gamma$, then $\Theta<0$ necessarily holds, which contradicts Assumption 1, and consequently, the long-run equilibrium becomes unstable. This implies that the long-run equilibrium in the wage-led growth regime is always unstable, and also that the Hopf bifurcation never occurs. Therefore, the reserve-army effect has a destabilizing effect.

From the above reasoning, the interaction between the reserve-army and reserve-armycreation effects plays an important role in stabilizing both the wage-led and profit-led growth regimes, and in the occurrence of the Hopf bifurcation.

\subsection{Comparative statics analysis}

This section investigates the effects of the shifts in the parameters on the long-run equilibrium. To conduct a comparative statics analysis, we need the stability of the equilibrium. For this reason, we assume $\Theta>0$ in the following analysis. As has been discussed above, the long-run equilibrium can be unstable. Therefore, we confine ourselves to the case where the long-run equilibrium is stable.

Table 1 summarizes the results of comparative statics in the four cases. ${ }^{25}$ In Table 1 , the "+" sign indicates that the corresponding variable increases with the parameter, while the "-" sign indicates that the corresponding variable decreases with the parameter. The signs "+/-" and " $-/+"$ indicate that an increase in the parameter either increases or decreases the corresponding variable. The mark " $\dagger$ " shows that the left-hand sign applies when $\Gamma<0$, while the right-hand sign applies when $\Gamma>0$.

Moreover, for the effect of $\theta$, we assume that $m_{f}-m_{w}(e)>0$. Firms attempt to set their target profit share as high as possible, whereas workers attempt to set their target profit share as low as possible. Therefore, this assumption is reasonable.

[Table 1 around here]

Let us explain the results in Table 1. Because of the limitations of space, we focus especially on the rate of employment.

\footnotetext{
${ }^{25}$ See Appendix for details.
} 


\section{- Savings rate}

An increase in the savings rate of capitalists decreases the rate of capacity utilization and the rate of capital accumulation. This negative effect on the growth rate is known as the "paradox of thrift." A rise in the savings rate decreases the rate of employment. Stockhammer (2004) also investigates the rate of employment in a Kaleckian framework. In Stockhammer's model, the long-run equilibrium value of the rate of employment consists of the exogenous natural rate of growth and the parameters of the investment function and the income distribution function, and does not depend on the savings rate. Hence, a change in the savings rate never affects the rate of employment. In our model, on the other hand, the natural rate of growth is endogenously determined, and accordingly, the change in the savings rate affects the rate of employment.

\section{- Labor supply growth}

Previous Kaleckian models cannot investigate the effect of supply side factors on equilibrium values. In contrast, our model can investigate these. In either case, an increase in $n$ lowers the rate of employment. Because the relation $g_{a}^{*}=s m^{*} u^{*}-n$ holds in the long-run equilibrium, an increase in $n$ has three different effects on $g_{a}^{*}$ and consequently, on $e^{*}$ : it directly decreases $g_{a}^{*}$ with the coefficient of $n$ being -1; it indirectly affects $g_{a}^{*}$ through $m^{*}$, which is positive when $\Gamma<0$ and negative when $\Gamma>0$; and it indirectly affects $g_{a}^{*}$ through $u^{*}$, which is negative when $\Gamma<0$ and positive when $\Gamma>0$. In total, the two negative effects outweigh the one positive effect, which leads to a decline in $g_{a}^{*}$ and $e^{*}$. Stockhammer (2004) also concludes that an increase in labor supply growth leads to a decrease in the rate of employment in the profit-led growth regime $(\beta>\gamma$ in our model), in which the long-run equilibrium is stable. Yet, the wage-led growth regime in Stockhammer's model $(\beta<\gamma$ in our model) is unstable, and thus, one cannot conduct a comparative statics analysis. In contrast, even the wage-led growth regime can be stable in our model.

- Relative bargaining power

An increase in the relative bargaining power of firms either increases or decreases the rate of employment depending on the size of the two elasticities of the investment function. The rate of employment decreases when $\beta<\gamma$, whereas it increases when $\beta>\gamma$. An increase in $\theta$ has two different effects on $g_{a}$ and $e$ : it indirectly increases $g_{a}$ and $e$ through its positive effect on $m$ and it indirectly decreases $g_{a}$ and $e$ through its negative effect on $u$. Whether or not the increase in $\theta$ leads to an increase in $g_{a}$ and $e$ depends on which effect dominates, which in turn depends on the size of the elasticities of the investment function. When $\beta<\gamma$, the negative effect of the capacity utilization dominates the positive effect of the profit share, thereby leading to a decrease in the growth rate of labor productivity and the employment rate. When $\beta>\gamma$, in contrast, the positive effect of the profit share dominates 
the negative effect of the capacity utilization, thereby leading to an increase in the growth rate of labor productivity and the employment rate.

Stockhammer (2004) also investigates the relationship between bargaining power and unemployment. He concludes that in the profit-led growth regime, a decrease in the bargaining power of workers leads to higher employment and lower unemployment. This result is consistent with our results. However, in the wage-led growth regime of Stockhammer's model, the long-run equilibrium is unstable, and consequently, one cannot investigate the relationship between bargaining power and unemployment. In our model, in contrast, thelong run equilibrium of the wage-led growth regime can be stable. In this case, we reach the opposite conclusion that an increase in the bargaining power of workers leads to higher employment and lower unemployment. This result is consistent with the empirical result of Storm and Naastepad (2007). Using data for 20 OECD countries during 1984-1997, they show that an increase in the bargaining power of firms because of labor market deregulation increases the unemployment rate; this is in contrast to the view of the mainstream theory.

\section{Numerical simulations}

In this section, we present numerical examples to show that, under plausible settings, an economically meaningful long-run equilibrium actually exists and limit cycles really occur. Note, however, that the results of numerical simulations depend on the specification of the functional form and the numerical values of the parameters.

For the numerical simulation, we have to specify the functional forms of equations (8) and (10). We specify these functions as follows:

$$
\begin{aligned}
m_{w}(e) & =\delta(1-e), \quad \delta>0, \\
g_{a}(e) & =\eta e, \quad \eta>0 .
\end{aligned}
$$

In this case, $\Gamma$ and $\Theta$ are respectively given by

$$
\begin{aligned}
& \Gamma=\eta-(1-\theta) \delta, \\
& \Theta=\eta-\frac{s(\beta-\gamma)}{1-\gamma}[\eta-(1-\theta) \delta] u .
\end{aligned}
$$

The equilibrium profit share $m^{*}$ satisfies the following equation:

$$
\Gamma \psi^{\frac{1}{1-\gamma}} S^{-\frac{\gamma}{1-\gamma}} m^{\frac{\beta-\gamma}{1-\gamma}}-\eta m+\eta\left[\theta m_{f}+(1-\theta) \delta\right]-\Gamma n=0 .
$$

From this, we obtain $m^{*}$, which we substitute in equation (17) to determine $u^{*}$. Furthermore, we substitute $m^{*}$ in the following equation to determine $e^{*}$ :

$$
e^{*}=\frac{m^{*}-\left[\theta m_{f}+(1-\theta) \delta\right]}{\Gamma} .
$$


We consider two cases depending on which is larger, $\beta$ or $\gamma$ given that $\Gamma<0$ is negative. ${ }^{26}$

\subsection{Case 1 (wage-led growth): $\beta<\gamma, \Gamma<0$}

Case 1 corresponds to the case where the elasticity of the investment rate with respect to the profit share is smaller than the elasticity of the investment rate with respect to the rate of capacity utilization, the reserve-army effect is strong, and the relative bargaining power of firms and the reserve-army-creation effect are weak. We set the parameters as follows:

$$
\beta=0.2, \gamma=0.4, \psi=0.15, s=0.6, \eta=0.1, \delta=0.5, \theta=0.25, m_{f}=0.3, n=0.015 \text {. }
$$

In this case, the long-run equilibrium values, $\Gamma$ and $\Theta$, yield the following: ${ }^{27}$

$$
u^{*}=0.74642, m^{*}=0.220134, e^{*}=0.835875, \Gamma=-0.275<0, \Theta=0.0589496>0 .
$$

These equilibrium values are economically meaningful. In addition, $\Theta>0$ is satisfied.

Figure 4 displays the solution path when the initial values and the speed of adjustment are set as $u(0)=0.7, m(0)=0.21, e(0)=0.8$, and $\alpha=4$. The figure shows a cyclical fluctuation. In Figure 4, we draw the solution path from $t=100$ to $t=200$, and upon performing the calculations further, we find that the solution path is not a perfect closed orbit and that it converges to the long-run equilibrium with rotation. Moreover, if we set the initial conditions further away from the long-run equilibrium, we find that the solution path diverges from the equilibrium. From these observations, we confirm that in this numerical example, the subcritical Hopf bifurcation occurs and the periodic solution is unstable.

Figure 5 projects the three-dimensional dynamics on the $(u, e)$-plane. The solution path starting from point $\mathrm{P}$ converges to the long-run equilibrium with rotation. In contrast, the solution path starting from point Q diverges from the long-run equilibrium with rotation. These phenomena correspond to the "corridor stability" of Leijonhufvud (1973).

Figure 6 shows the graphs of $a_{2}(\alpha)$ and $\phi(\alpha)$. We find that $\bar{\alpha}=4.61097$ and $\underline{\alpha}=4.02288$. In Figure 4, we use $\alpha=4$, from which we have $4<\underline{\alpha}$. Therefore, the subcritical Hopf bifurcation certainly occurs in this case. ${ }^{28}$ Moreover, if we choose $\alpha$ larger than $\underline{\alpha}$, we find

\footnotetext{
${ }^{26}$ Note that if $\Gamma>0$, the long-run equilibrium is almost always stable (see Proposition 1) and limit cycles never occur. Numerical simulations in stable cases are shown in the discussion paper version of the present paper.

${ }^{27}$ From these numerical settings, we obtain two values of $m$ within the range $m \in(0,1): m_{1}^{*}=0.220134$ and $m_{2}^{*}=0.0516332$. However, from $m_{2}^{*}$, we obtain $u^{*}=5.16014$ and $e^{*}=1.44861$, which are unrealistic. For this reason, we do not adopt $m_{2}^{*}$.

${ }^{28}$ In this numerical example, the range of $\alpha$ is such that both $a_{2}(\alpha)>0$ and $\phi(\alpha)<0$ are narrow. However, we can widen the range by choosing different parameter settings.
} 
that the solution path diverges irrespective of the initial conditions. This confirms that the subcritical Hopf bifurcation occurs at $\underline{\alpha}$.

Note, however, that the Hopf bifurcation that occurs in case 1 is not always the subcritical Hopf bifurcation. We can find a numerical example wherein the supercritical Hopf bifurcation occurs in case $1 .{ }^{29}$

[Figures 4, 5, and 6 around here]

Finally, Figures 7, 8, and 9 show cyclical patterns in the $(e, m)-,(u, m)-$, and $(e, u)$ planes. In the $(e, m)$-plane, clockwise cycles emerge whereas in the $(u, m)$ - and $(e, u)$-planes, counterclockwise cycles emerge. These cyclical patterns are consistent with some empirical findings stated in Introduction. Therefore, the type of cyclical fluctuations produced by our model matches empirical findings.

[Figures 7, 8, and 9 around here]

\subsection{Case 2 (profit-led growth): $\beta>\gamma, \Gamma<0$}

Case 2 corresponds to the case where the elasticity of the investment rate with respect to the profit share is larger than the elasticity of the investment rate with respect to the rate of capacity utilization, the reserve-army effect is strong, and the relative bargaining power of firms and the reserve-army-creation effect are weak. We set the parameters as follows:

$$
\beta=0.4, \gamma=0.2, \psi=0.2, s=0.6, \eta=0.1, \delta=1, \theta=0.25, m_{f}=0.3, n=0.016 .
$$

Here, the long-run equilibrium values, $\Gamma$ and $\Theta$, yield the following:

$$
u^{*}=0.741857, m^{*}=0.238619, e^{*}=0.902125, \Gamma=-0.65<0, \Theta=0.172331>0 .
$$

These equilibrium values are economically meaningful. In addition, $\Theta>0$ is satisfied.

Figure 10 displays the solution path when $u(0)=0.7, m(0)=0.2, e(0)=0.9$, and $\alpha=2$. The figure shows a cyclical fluctuation. Using various initial values, we find that in this case, a stable limit cycle emerges: any initial point converges to the limit cycle with rotation. Therefore, the supercritical Hopf bifurcation occurs in case 2.

Figure 11 shows the graphs of $a_{2}(\alpha)$ and $\phi(\alpha)$. We find that $\bar{\alpha}=2.34506$ and $\underline{\alpha}=$ 1.95504. In Figure 10, we use $\alpha=2$, from which we have $\underline{\alpha}<2$. Therefore, the supercritical Hopf bifurcation certainly occurs in this case. ${ }^{30}$

\footnotetext{
${ }^{29}$ Under the parameters $\beta=0.4, \gamma=0.41, \psi=0.2, s=0.6, \eta=0.1, \delta=1$, and $\theta=0.25$, the Hopf bifurcation point leads to $\underline{\alpha}=2.56626$, and there exists a stable limit cycle at $\alpha>\underline{\alpha}$.

${ }^{30}$ In this case, as in case 1 , the range of $\alpha$ is such that both $a_{2}(\alpha)>0$ and $\phi(\alpha)<0$ are narrow. However, we can widen the range by choosing different parameter settings. Note that we were unable to find a numerical example that produced subcritical Hopf bifurcation.
} 
[Figures 10 and 11 around here]

In case 2 as in case 1 , though we do not present figures because of limitation of space, we obtain clockwise cycles in the $(e, m)$-plane and counterclockwise cycles in the $(u, m)$ and $(e, u)$-planes. ${ }^{31}$

\section{Concluding remarks}

In this paper, we have developed a demand-led growth model that considers elements from Goodwin, Kalecki, and Marx. More specifically, we have presented a Kaleckian model that describes a labor-constrained economy. In the model, we have considered the two opposing effects caused by an increase in the rate of employment. One is the reserve-army effect: as the labor market tightens and labor shortage becomes clearer, the bargaining power of workers increases, which exerts an upward pressure on wages. The other is the reservearmy-creation effect: such an upward pressure on wages leads firms to adopt labor-saving technical changes to intentionally create the reserve-army of labor.

We have presented the two cases that produce limit cycles according to the size of parameters of the investment function, the relative bargaining power of firms, the reservearmy effect, and the reserve-army-creation effect. These two cases correspond to the case where the relative bargaining power of firms is weak, the reserve-army effect is strong, and the reserve-army-creation effect is weak. Our theoretical analysis and numerical examples show that limit cycles occur in both wage-led growth and profit-led growth, which implies that perpetual business cycles are inherent in capitalist economies.

Using the model, we have analyzed how the relative bargaining power of workers and firms affects the long-run equilibrium rate of employment. The relationship between the bargaining power and the employment rate differs depending on the regime of the long-run equilibrium. If the long-run equilibrium is characterized as the wage-led growth regime, a rise in the relative bargaining power of workers increases the employment rate. If, on the other hand, the long-run equilibrium is characterized as the profit-led growth regime, a rise in the relative bargaining power of workers decreases the employment rate.

Note, however, that in the wage-led growth regime, an increase in the workers' bargaining power leads to higher employment, but it simultaneously leads to lower profit share: the

\footnotetext{
${ }^{31}$ Depending on conditions, our model produces clockwise cycles in the all three planes as observed in the US by Zipperer and Skott (2011). For example, if the long-run equilibrium exhibits the exhilarationist regime, if the reserve army creation effect is weak, and if the reserve army effect is strong, then clockwise cycles can occur.
} 
workers' interests interfere with firms' interests. For this reason, it may be difficult to implement an economic policy intended to adjust the bargaining power of both classes. Even in this case, nonetheless, the demand stimulation policy is effective. The stimulation of effective demand brings about higher employment and accordingly, lower unemployment.

\section{Acknowledgement}

I would like to thank two anonymous referees, seminar participants at Nishogakusha University and Chuo University for their useful comments and suggestions, which have substantially improved the paper.

\section{References}

Aghion, P., Howitt, P., 1992. A model of growth through creative destruction. Econometrica 60 (2), 323-351.

Arrow, K.J., 1962. The economic implications of learning by doing. Review of Economic Studies 29 (3), 155-173.

Asada, T., Semmler, W., 1995. Growth and finance: an intertemporal model. Journal of Macroeconomics 17 (4), 623-649.

Barbosa-Filho, N.H., Taylor, L., 2006. Distributive and demand cycles in the US economyA structuralist Goodwin model. Metroeconomica 57 (3), 389-411.

Benhabib, J., Nishimura, K., 1979. The Hopf-bifurcation and the existence and stability of closed orbits in multisector models of optimal economic growth. Journal of Economic Theory 21 (3), 421-444.

Bhaduri, A., 2006. Endogenous economic growth: a new approach. Cambridge Journal of Economics 30, 69-83.

Blecker, R.A., 2002. Distribution, demand and growth in neo-Kaleckian macro-models. In: M. Setterfield, M. (Ed.). The Economics of Demand-led Growth, Challenging the Supply-side Vision of the Long Run. Cheltenham: Edward Elgar.

Cassetti, M., 2003. Bargaining power, effective demand and technical progress: a Kaleckian model of growth. Cambridge Journal of Economics 27, 449-464.

Choi, H., 1995. Goodwin's growth cycle and the efficiency wage hypothesis. Journal of Economic Behavior \& Organization 27, 223-235. 
Dockner, E.J., Feichtinger, G., 1991. On the optimality of limit cycles in dynamic economic systems. Journal of Economics 53 (1), 31-50.

Dutt, A.K., 1992 Conflict inflation, distribution, cyclical accumulation and crises. European Journal of Political Economy 8 (4), 579-597.

Dutt, A.K., Amadeo, E.J., 1993. A post-Keynesian theory of growth, interest and money. In: Baranzini, M., Harcourt, G.C. (Eds.). The Dynamics of the Wealth of Nations: Growth, Distribution and Structural Change. New York: St.Martin's Press.

Dutt, A.K., 2006. Aggregate demand, aggregate supply and economic growth. International Review of Applied Economics 20, 319-336.

Evans, G.W., Honkapohja, S., Romer, P., 1998. Growth cycles. American Economic Review 88 (3), 495-515.

Flaschel, P., Skott, P., 2006. Steindlian models of growth and stagnation. Metroeconomica 57 (3), 303-338.

Foley, D.K., 2003. Endogenous technical change with externalities in a classical growth model. Journal of Economic Behavior \& Organization 52, 167-189.

Francois, P., Lloyd-Ellis, H., 2003. Animal spirits through creative destruction. American Economic Review 93 (3), 530-550.

Furukawa, Y., 2007. Endogenous growth cycles. Journal of Economics 91 (1), 69-96.

Gandolfo, G., 2010. Economic Dynamics, 4th edition. Berlin: Springer-Verlag.

Goodwin, R., 1967. A growth cycle. In: Feinstein, C.H. (Ed.). Socialism, Capitalism and Economic Growth, Essays Presented to Maurice Dobb. Cambridge: Cambridge University Press, 54-58.

Grossman, G.M., Helpman, E., 1991. Quality ladders in the theory of growth. Review of Economic Studies 58 (1), 43-61.

Harvie, D., 2000. Testing Goodwin: growth cycles in ten OECD. Cambridge Journal of Economics 24 (3), 349-376.

Kalecki, M., 1971. Selected Essays on the Dynamics of the Capitalist Economy. Cambridge: Cambridge University Press.

Lavoie, M., 1992. Foundations of Post-Keynesian Economic Analysis. Cheltenham: Edward Elgar.

Leijonhufvud, A., 1973. Effective demand failures. Swedish Journal of Economics 75, $27-48$. 
León-Ledesma, M.A., Thirlwall, A.P., 2002. The endogeneity of the natural rate of growth. Cambridge Journal of Economics 26, 441-459.

Libânio, G.A., 2009 Aggregate demand and the endogeneity of the natural rate of growth: evidence from Latin American economies. Cambridge Journal of Economics. doi:10.1093/cje/ben059.

Lima, G.T., 2004. Endogenous technological innovation, capital accumulation and distributional dynamics. Metroeconomica 55, 386-408.

Marglin, S., Bhaduri, A., 1990. Profit squeeze and Keynesian theory. In: Marglin, S., Schor, J. (Eds.). The Golden Age of Capitalism: Reinterpreting the Postwar Experience. Oxford: Clarendon Press.

Marquetti, A., 2004. Do rising real wages increase the rate of labor-saving technical change? Some econometric evidence. Metroeconomica 55 (4), 432-441.

Marx, K., 1976. Capital, Vol. 1. Harmondsworth: Penguin.

Mohun, S., Veneziani, R., 2008. Goodwin cycles and the US economy, 1948-2004. In: Flaschel, P, Landesmann, M. (Eds.). Mathematical Economics and the Dynamics of Capitalism. London: Routledge.

van der Ploeg, F., 1987. Growth cycles, induced technical change, and perpetual conflict over the distribution if income. Journal of Macroeconomics 9 (1), 1-12.

Pohjola, M.T., 1981. Stable, cyclic and chaotic growth: the dynamics of a discrete-time version of Goodwin's growth cycle model. Journal of Economics 41 (1-2), 27-38.

Raghavendra, S., 2006. Limits to investment exhilarationism. Journal of Economics 87, 257-280.

Romer, P.M., 1990. Endogenous technological change. Journal of Political Economy 98 (5), 71-101.

Rowthorn, R.E., 1977. Conflict, inflation and money. Cambridge Journal of Economics 1 (3), 215-239.

Ryzhenkov, A.V., 2009. A Goodwinian model with direct and roundabout returns to scale (an application to Italy). Metroeconomica 60 (3), 343-399.

Sasaki, H., 2009. Cyclical growth in a Goodwin-Kalecki-Marx model. Tohoku Economics Research Group Discussion Papers, No. 246.

Sasaki, H., 2010. Endogenous technological change, income distribution, and unemployment with inter-class conflict. Structural Change and Economic Dynamics 21 (2), 123-134. 
Sasaki, H., 2011. Conflict, growth, distribution, and employment: a long-run Kaleckian model. International Review of Applied Economics 25 (5), 539-557.

Sato, Y., 1985. Marx-Goodwin growth cycles in a two-sector economy. Journal of Economics 45 (1), 21-34.

Shah, A., Desai, M., 1981. Growth cycles with induced technical change. Economic Journal 91, 1006-1010.

Skott, P., 1989. Effective demand, class struggle and cyclical growth. International Economic Review 30 (1), 231-247.

Skott, P., 2012. Theoretical and empirical shortcomings of the Kaleckian investment function. Metroeconomica 63 (1), 109-138.

Skott, P., Zipperer, B., 2010. An empirical evaluation of three post Keynesian models. Working Paper 2010-08, University of Massachusetts Amherst.

Sportelli, M.C., 1995. A Kolmogoroff generalized predator-prey model of Goodwin's growth cycle. Journal of Economics 61 (1), 35-64.

Sportelli, M.C., 2000. Dynamic complexity in a Keynesian growth-cycle model involving Harrod's instability. Journal of Economics 71 (2), 167-198.

Stockhammer, E., 2004 Is there an equilibrium rate of unemployment in the long run? Review of Political Economy 16, 59-77.

Storm, S., Naastepad, C.W.M., 2007. It is high time to ditch the NAIRU. Journal of Post Keynesian Economics 29 (4), 531-554.

Velupillai, K.V., 2006. A disequilibrium macrodynamic model of fluctuations. Journal of Macroeconomics 28 (1), 752-767.

Wälde, K., 2005. Endogenous growth cycles. International Economic Review 46 (3), 867894.

Wolfstetter, E., 1982. Fiscal policy and the classical growth cycle. Journal of Economics 42 (4), 375-393.

Yoshida, H., 1999. Harrod's “Knife-Edge" reconsidered: an application of the Hopf bifurcation theorem and numerical simulations. Journal of Macroeconomics 21 (3), 537-562.

Zipperer, B., Skott, P., 2011. Cyclical patterns of employment, utilization, and profitability. Journal of Post Keynesian Economics 34 (1), 25-57. 


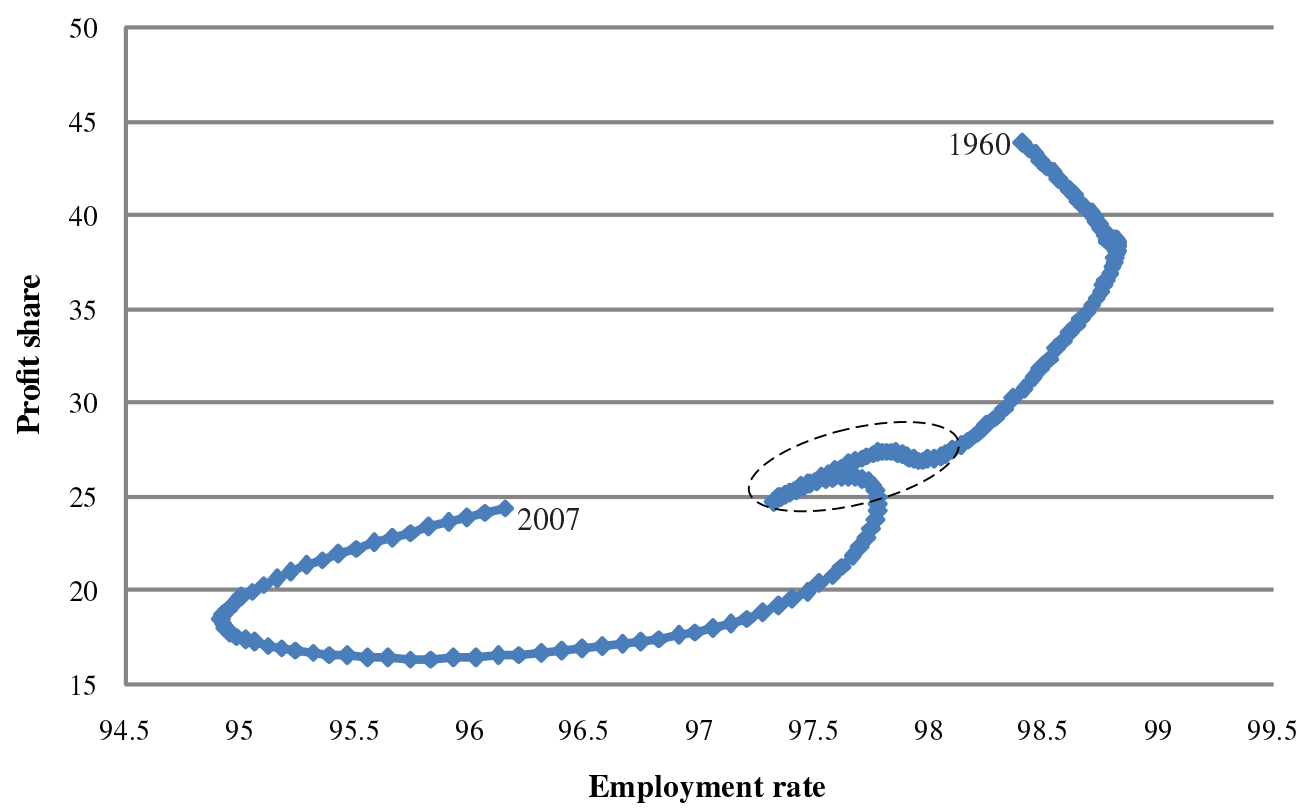

Figure 1: Smoothed cycle in the $(e, m)$-plane in Japan

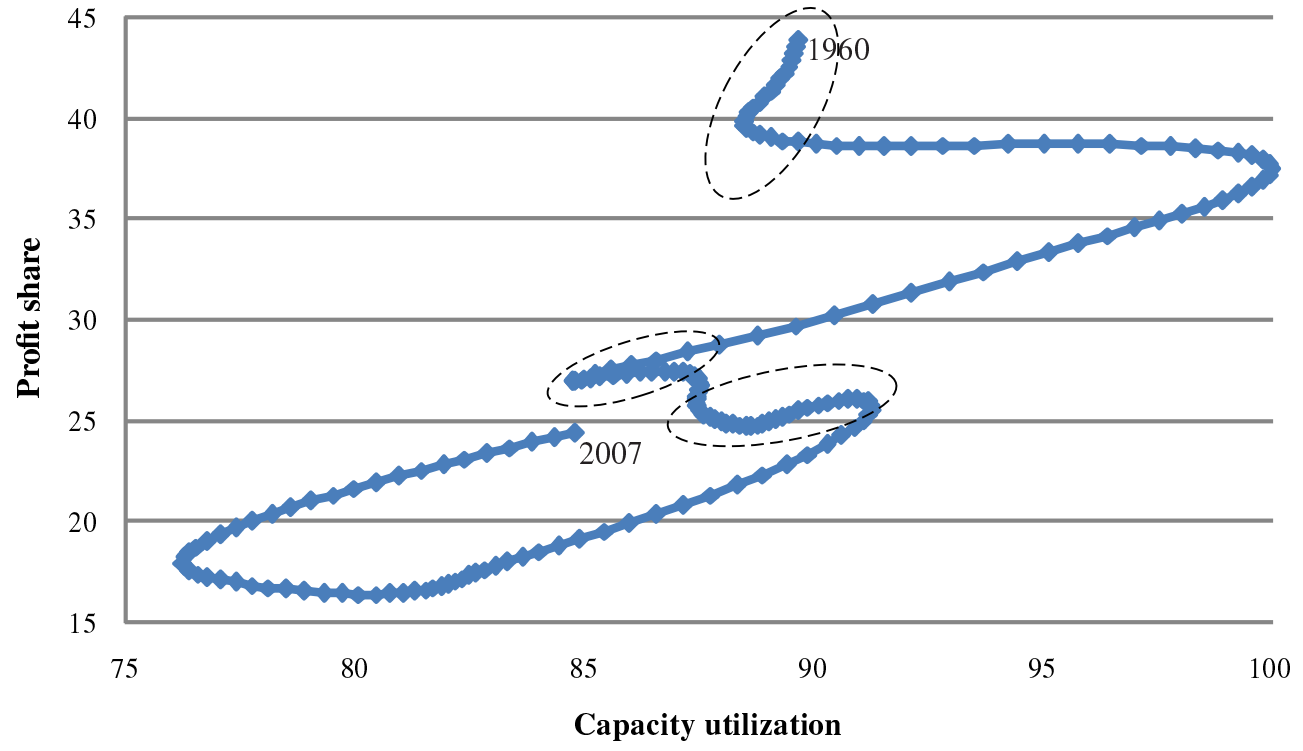

Figure 2: Smoothed cycle in the $(u, m)$-plane in Japan 


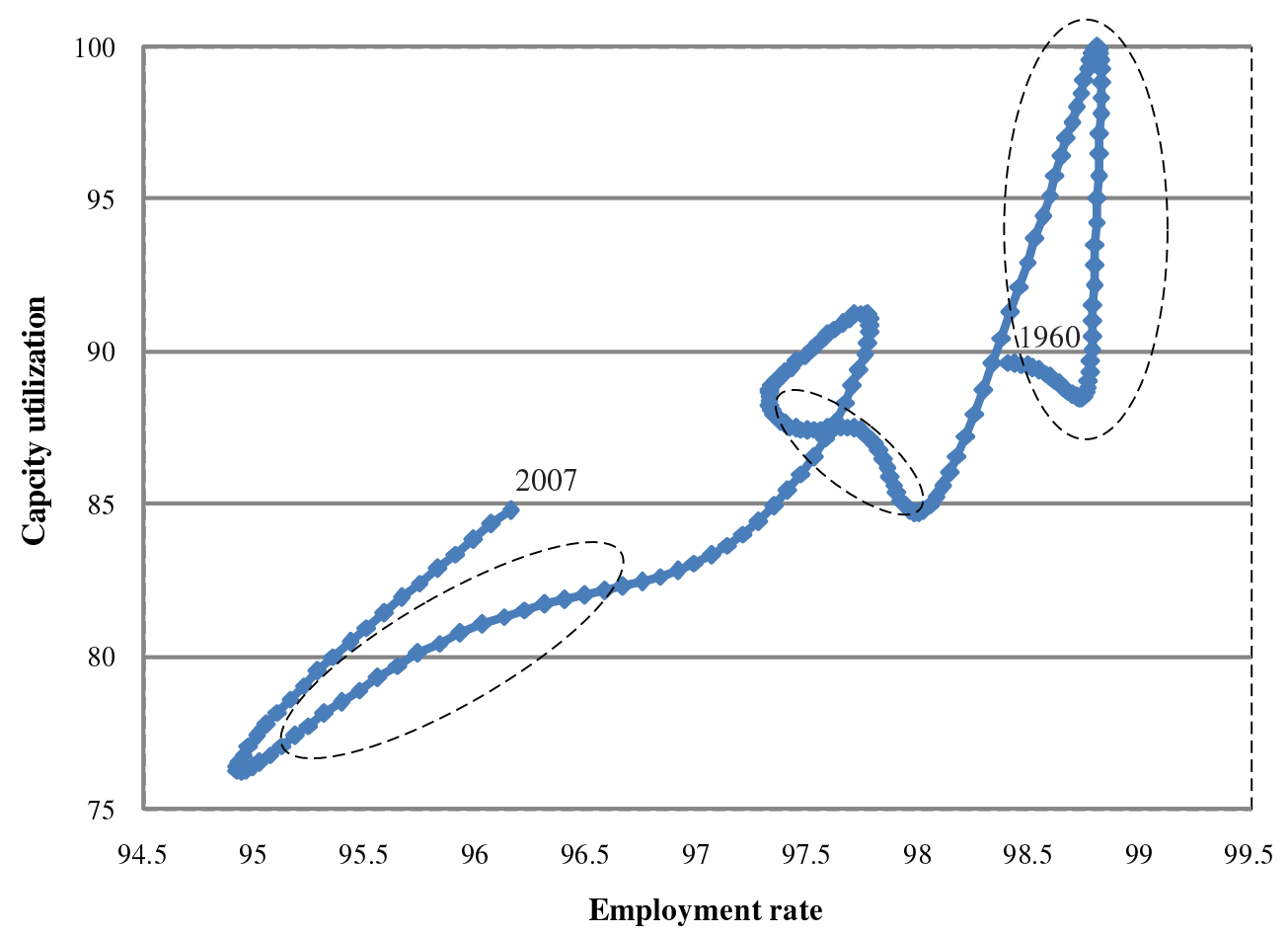

Figure 3: Smoothed cycle in the $(e, u)$-plane in Japan

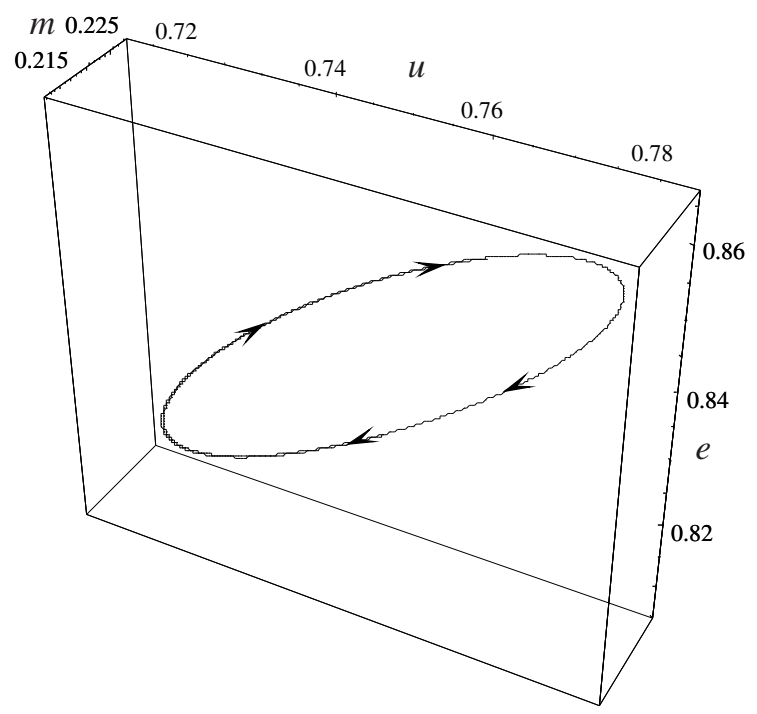

Figure 4: Solution path in case $1(\alpha=4)$ 


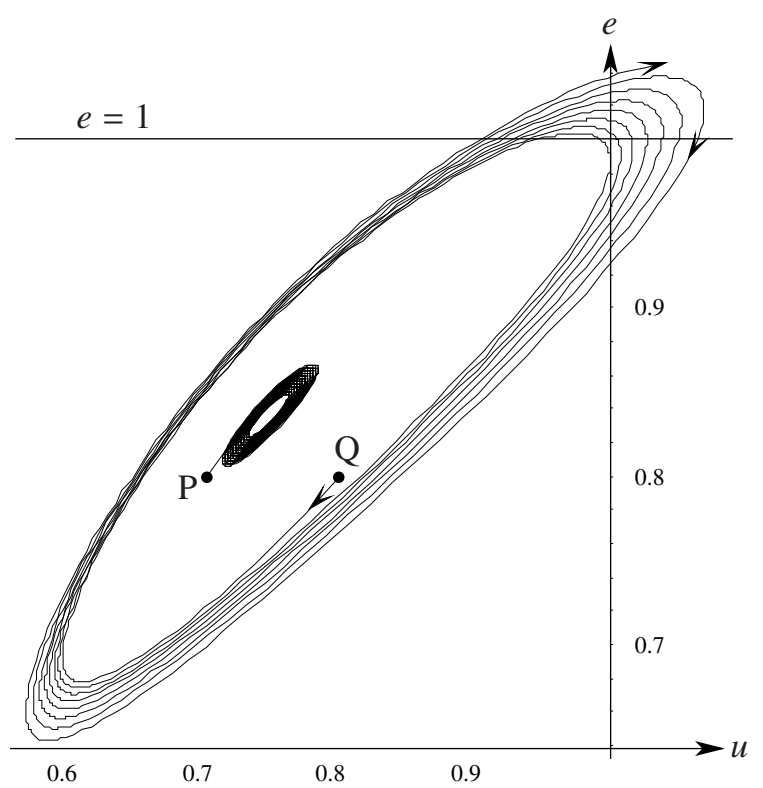

Figure 5: Solution paths starting from different initial values in case $1(\alpha=4)$

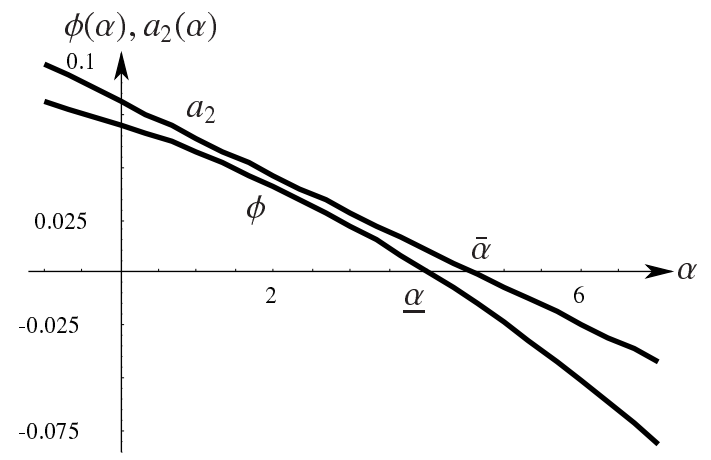

Figure 6: Graphs of $a_{2}(\alpha)$ and $\phi(\alpha)$ in case 1

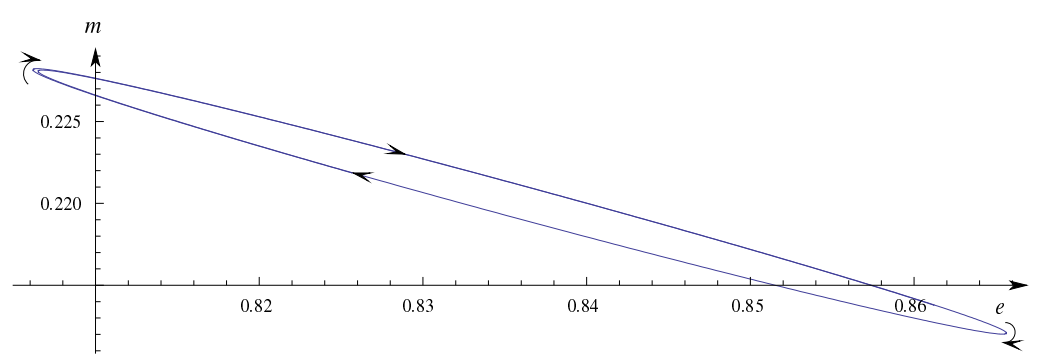

Figure 7: Clockwise cycles in the $(e, m)$-plane in case 1 


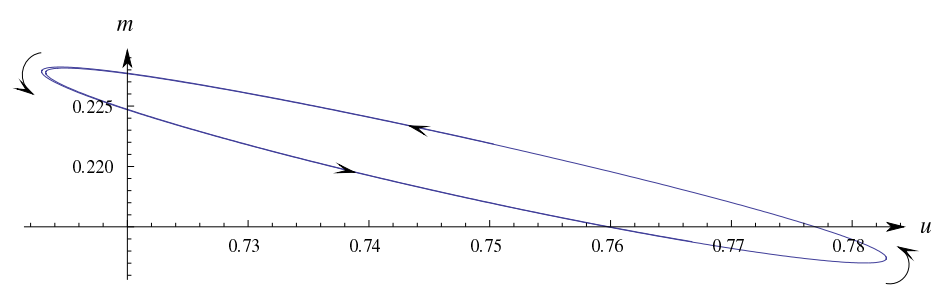

Figure 8: Counterclockwise cycles in the $(u, m)$-plane in case 1

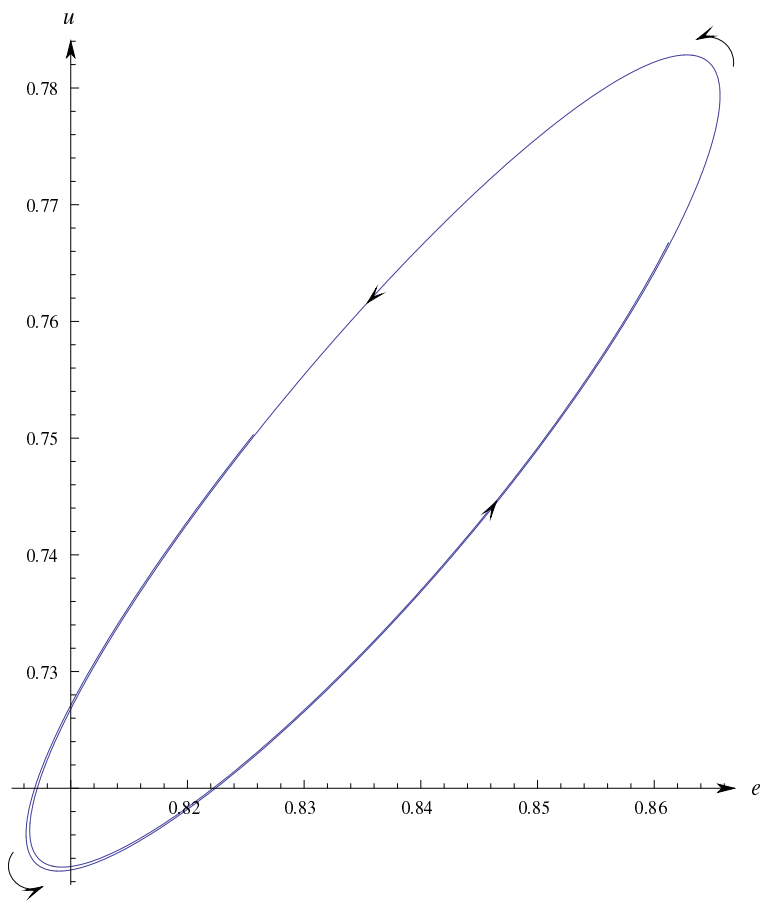

Figure 9: Counterclockwise cycles in the $(e, u)$-plane in case 1 


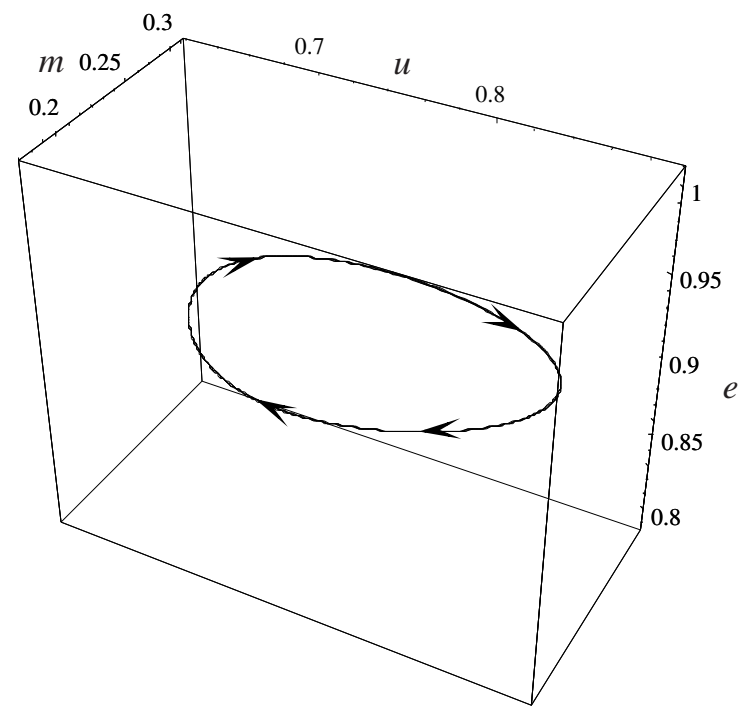

Figure 10: Solution path in case $2(\alpha=2)$

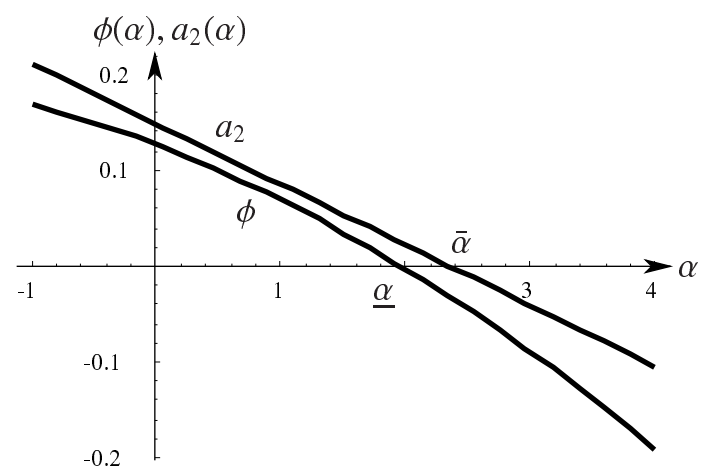

Figure 11: Graphs of $a_{2}(\alpha)$ and $\phi(\alpha)$ in case 2 
Table 1: Results of comparative statics analysis

\begin{tabular}{rccccc}
\hline$\beta<\gamma$ & $s$ & $n$ & $\theta$ & $m_{f}$ & $\psi$ \\
\hline$u^{*}$ & - & $-/+^{\dagger}$ & - & - & $++^{\dagger}$ \\
$m^{*}$ & $+/-^{\dagger}$ & $+/-^{\dagger}$ & + & + & $-/+^{\dagger}$ \\
$e^{*}, g_{a}^{*}$ & - & - & - & - & + \\
$g^{*}$ & - & $-/+^{\dagger}$ & - & - & + \\
\hline \hline$\beta>\gamma$ & $s$ & $n$ & $\theta$ & $m_{f}$ & $\psi$ \\
\hline$u^{*}$ & - & $-/+^{\dagger}$ & - & - & $++^{\ddagger}$ \\
$m^{*}$ & $+/-^{\dagger}$ & $+/-^{\dagger}$ & + & + & $-/+^{\dagger}$ \\
$e^{*}, g_{a}^{*}$ & - & - & + & + & + \\
$g^{*}$ & - & $+/-^{\dagger}$ & + & + & + \\
\hline
\end{tabular}

$\dagger$ When $\Gamma<0$, the left-hand sign applies, and when $\Gamma>0$, the right-hand sign applies.

$¥$ These signs are obtained by numerical calculations. 


\section{A Appendix}

The effects of a rise in parameters on the long-run equilibrium values are as follows.

- The rate of capacity utilization

$$
\begin{aligned}
\frac{d u^{*}}{d s} & =\frac{u^{*}\left[s \beta u^{*}(1-\theta) m_{w}^{\prime}\left(e^{*}\right)-\left(1-s \beta u^{*}\right) g_{a}^{\prime}\left(e^{*}\right)\right]}{s(1-\gamma) \Theta}<0, \\
\frac{d u^{*}}{d n} & =\frac{(1-\beta) u^{*} \Gamma}{(1-\gamma) m^{*} \Theta} \gtrless 0, \\
\frac{d u^{*}}{d \theta} & =-\frac{(1-\beta) u^{*} g_{a}^{\prime}\left(e^{*}\right)\left[m_{f}-m_{w}\left(e^{*}\right)\right]}{(1-\gamma) m^{*} \Theta}<0, \\
\frac{d u^{*}}{d m_{f}} & =-\frac{\theta(1-\beta) u^{*} g_{a}^{\prime}\left(e^{*}\right)}{(1-\gamma) m^{*} \Theta}<0, \\
\frac{d u^{*}}{d \psi} & =\frac{u^{*}\left[(1-\gamma) \Theta-s(1-\beta) m^{*} \Gamma\right]}{\psi(1-\gamma)^{2} \Theta} .
\end{aligned}
$$

- The profit share

$$
\begin{aligned}
\frac{d m^{*}}{d s} & =-\frac{\gamma u^{*} m^{*} \Gamma}{(1-\gamma) \Theta} \gtrless 0, \\
\frac{d m^{*}}{d n} & =-\frac{\Gamma}{\Theta} \gtrless 0, \\
\frac{d m^{*}}{d \theta} & =\frac{g_{a}^{\prime}\left(e^{*}\right)\left[m_{f}-m_{w}\left(e^{*}\right)\right]}{\Theta}>0, \\
\frac{d m^{*}}{d m_{f}} & =\frac{\theta g_{a}^{\prime}\left(e^{*}\right)}{\Theta}>0, \\
\frac{d m^{*}}{d \psi} & =\frac{s m^{*} u^{*} \Gamma}{\psi(1-\gamma) \Theta} \gtrless 0 .
\end{aligned}
$$

- The rate of employment

$$
\begin{aligned}
\frac{d e^{*}}{d s} & =-\frac{\gamma u^{*} m^{*}}{(1-\gamma) \Theta}<0, \\
\frac{d e^{*}}{d n} & =-\frac{1}{\Theta}<0, \\
\frac{d e^{*}}{d \theta} & =\frac{s(\beta-\gamma) u^{*}\left[m_{f}-m_{w}\left(e^{*}\right)\right]}{(1-\gamma) \Theta} \gtrless 0, \\
\frac{d e^{*}}{d m_{f}} & =\frac{\theta s(\beta-\gamma) u^{*}}{(1-\gamma) \Theta} \gtrless 0, \\
\frac{d e^{*}}{d \psi} & =\frac{s m^{*} u^{*}}{\psi(1-\gamma) \Theta}>0 .
\end{aligned}
$$


- The rate of capital accumulation

$$
\begin{aligned}
\frac{d g^{*}}{d s} & =-\frac{\gamma m^{*} u^{*} g_{a}^{\prime}\left(e^{*}\right)}{(1-\gamma) \Theta}<0, \\
\frac{d g^{*}}{d n} & =-\frac{s(\beta-\gamma) u^{*} \Gamma}{(1-\gamma) \Theta} \gtrless 0, \\
\frac{d g^{*}}{d \theta} & =\frac{s(\beta-\gamma) u^{*} g_{a}^{\prime}\left(e^{*}\right)\left[m_{f}-m_{w}\left(e^{*}\right)\right]}{(1-\gamma) \Theta} \gtrless 0, \\
\frac{d g^{*}}{d m_{f}} & =\frac{\theta s(\beta-\gamma) u^{*} g_{a}^{\prime}\left(e^{*}\right)}{(1-\gamma) \Theta} \gtrless 0, \\
\frac{d g^{*}}{d \psi} & =\frac{s m^{*} u^{*} g_{a}^{\prime}\left(e^{*}\right)}{\psi(1-\gamma) \Theta}>0 .
\end{aligned}
$$

